\title{
INFECTIOUS DISEASES, NSW: OCTOBER 1999
}

\section{TRENDS}

Reports of notifiable diseases to the end of August were largely unremarkable for this time of year (Figure 2, Table 3 ). However, 27 cases of meningococcal disease were reported for August, part of the expected late-winter, earlyspring peak for this disease.

\section{NSW INFLUENZA SURVEILLANCE ACTIVITY UPDATE}

\section{Summary}

Influenza activity reached a plateau in early September. In August, influenza A declined sharply, and influenza B emerged as the dominant strain. However, this activity has since declined. While the influenza season arrived earlier in 1999 than in the previous few years, activity has not exceeded the peaks recorded in recent years.

\section{Clinical activity}

Rates of reported influenza-like illness varied during August and early September but remained below the peak reached in early July (Figure 3). Reports were received from more than 30 sentinel general practitioners (GPs) through four Public Health Units, including more than 4,000 consultations. However, this source of data may include illness due to causes other than influenza.

\section{Virological activity}

The laboratory reporting rate for influenza A continued to decline during August and early September. Reporting of influenza B increased and peaked in mid-August (Figure 4). In the second week of September 9 cases of influenza A were reported ( 7 virological, 2 serological), 18 cases of influenza B (13 virological, 5 serological) and 39 of respiratory syncitical virus (RSV). In the same week last year, there were 18 cases of influenza $\mathrm{A}$, no cases of influenza B and 55 cases of RSV. This data source tends to include a high proportion of hospitalised patients, particularly children, and may not accurately reflect the effect of these diseases on other sections of the community.

\section{Directed virological surveillance}

The number of samples submitted for viral examination as part of this special surveillance program decreased markedly from 34 (3 positive for influenza A, 6 for influenza B) in the first week of August to 5 (none of which were positive for any respiratory virus) in the second week of September. This probably reflects a decrease in the number of patients presenting with influenza-like illness to participating sentinel GPs. This trend is consistent with the other data sources discussed previously; that is, the influenza isolation rate has been variable during August and early September, influenza A decreased markedly in early August, and influenza B remained higher and decreased in September.
The sentinel GPs participating in the scheme this year are from Central Sydney, South Eastern Sydney, Western Sydney, Wentworth, Central Coast, Hunter, Illawarra, Greater Murray and Southern Areas.

\section{International surveillance}

Few reports of influenza were received by the World Health Organization during August. Activity in the Southern Hemisphere this winter has varied considerably between countries, but high levels have rarely been reported. New Zealand reported a decline in cases since the first two weeks of July, with more influenza A than B reported. Argentina reported influenza A activity at the level of 'widespread outbreak' for the month of July. South Africa continues to report sporadic influenza activity for the week ending 17 August, with more cases of influenza B than A; and Chile and Paraguay both reported 'sporadic' activity of influenza A.

In the Northern Hemisphere, Israel reported two cases of influenza in the last week of July, one each of influenza A and B. Brazil reported a 'local outbreak' of influenza A activity during the first week of August, Thailand reported 'sporadic activity' of influenza A from May to the end of July.

\section{MANAGEMENT OF MULTI-DRUG-RESISTANT TUBERCULOSIS IN NSW}

Australia is fortunate to have one of the world's lowest tuberculosis rates. This has been achieved and maintained by the success of the post-World War II national tuberculosis campaign; continued commitment of dedicated tuberculosis services by state and federal governments; and the worldwide downward trend in tuberculosis incidence this century.

The National Health and Medical Research Council (NH\&MRC) Tuberculosis Working Party identified the main threats to the control of tuberculosis in Australia to be inappropriate or inadequate approaches to tuberculosis treatment in persons born overseas and an increase in the rate of multi-drug-resistant tuberculosis (MDR TB). ${ }^{1}$

MDR TB is defined as bacilli that are identified in vitro as resistant to at least isoniazid and rifampicin, the main drugs used to treat tuberculosis. ${ }^{2}$ MDR TB represents an important public health concern for the effective control of tuberculosis.

The development of drug-resistant bacilli relate directly to error in the: ${ }^{2}$

- prescription of chemotherapy

- management of drug supply

- inappropriate management of cases

- ineffective administration of drugs to the patient.

continued on page 143 


\section{FIGURE 2}

REPORTS OF SELECTED INFECTIOUS DISEASES, NSW, JANUARY 1994 TO AUGUST 1999, BY MONTH OF ONSET

These are preliminary data: case counts in recent months may increase because of reporting delays
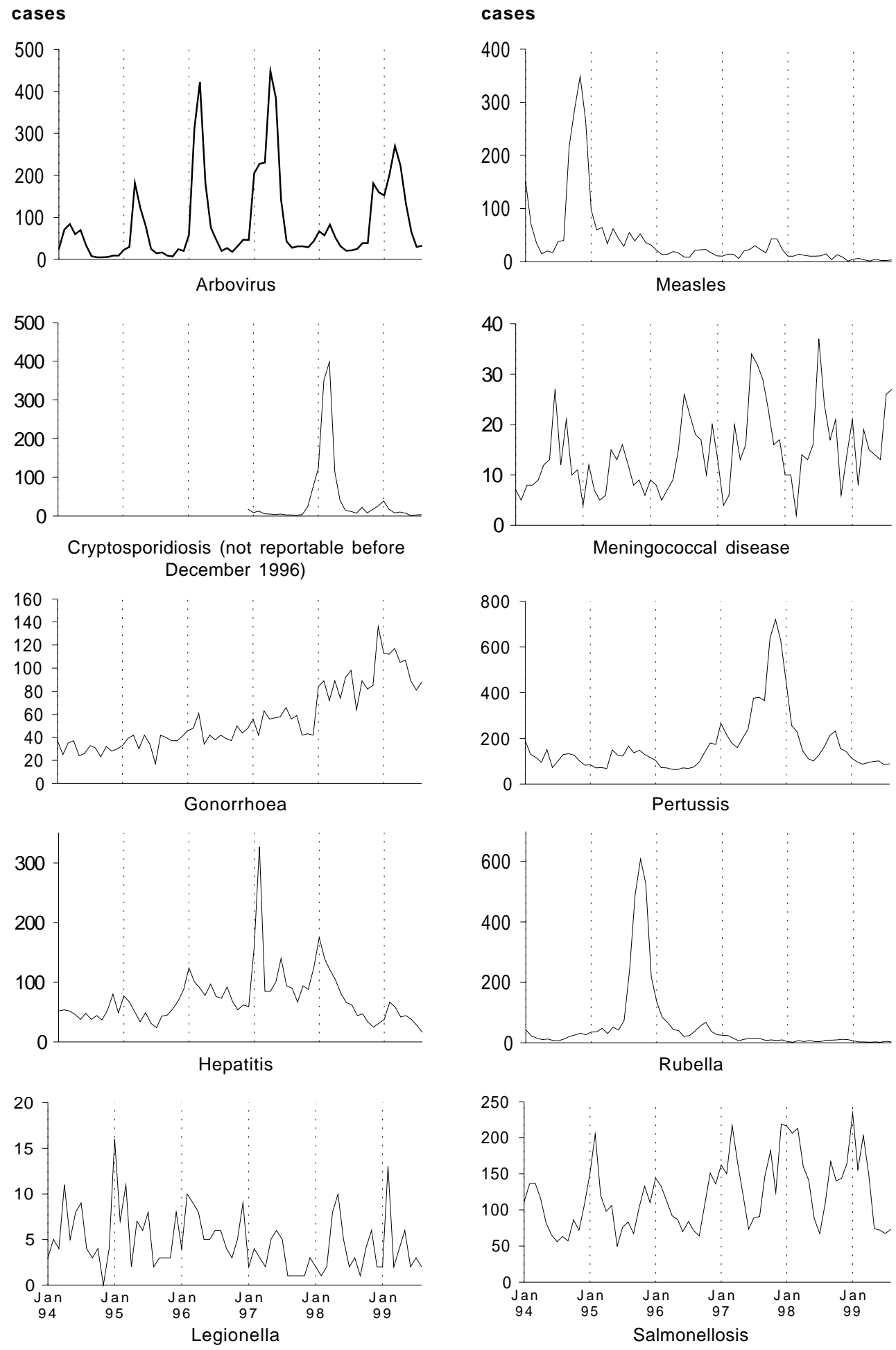


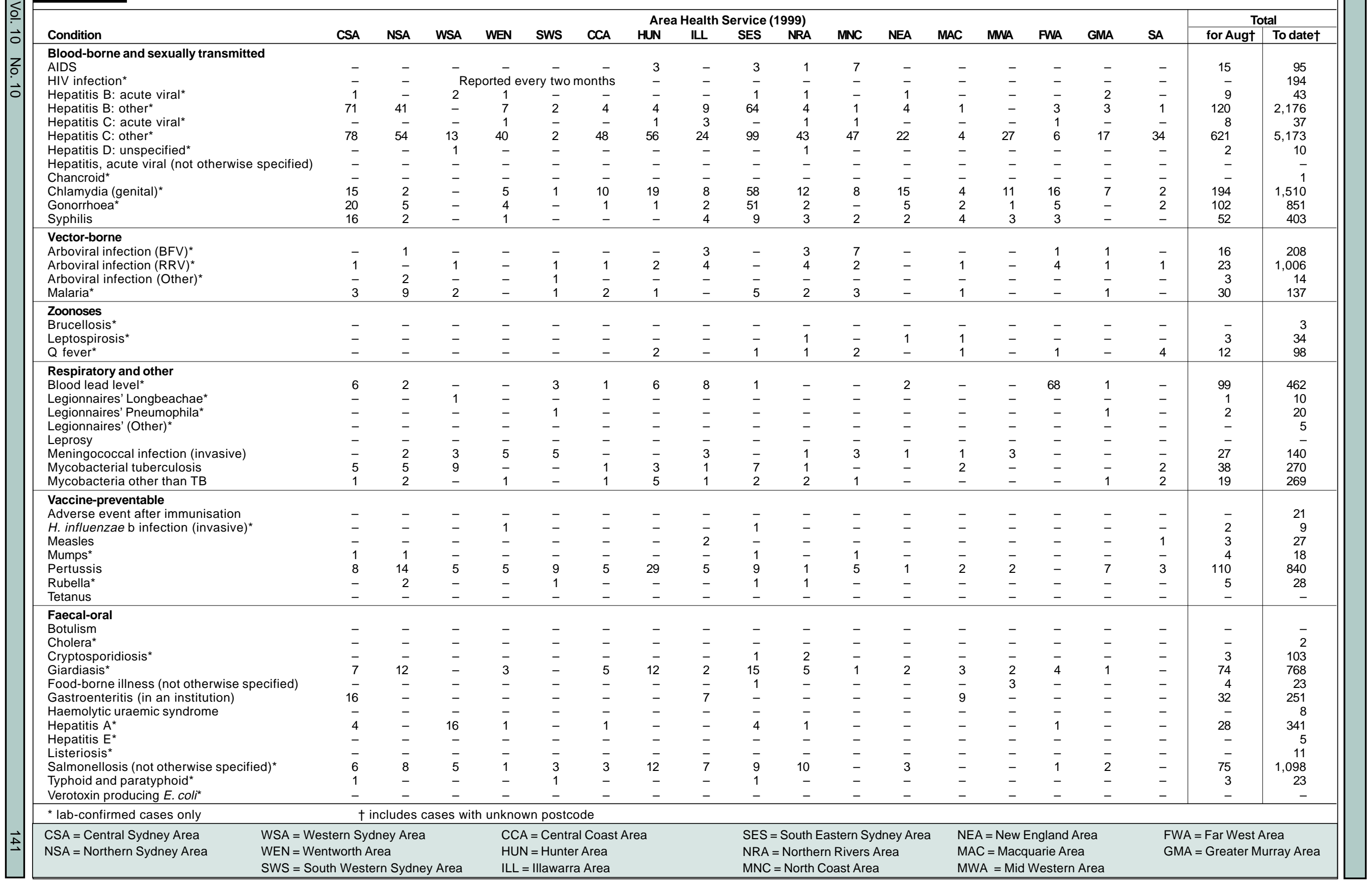




\section{FIGURE 3}

NSW GP SENTINEL SURVEILLANCE-INFLUENZA-LIKE ILLNESS, BY WEEK OF CONSULTATION, WITH HISTORICAL COMPARISONS

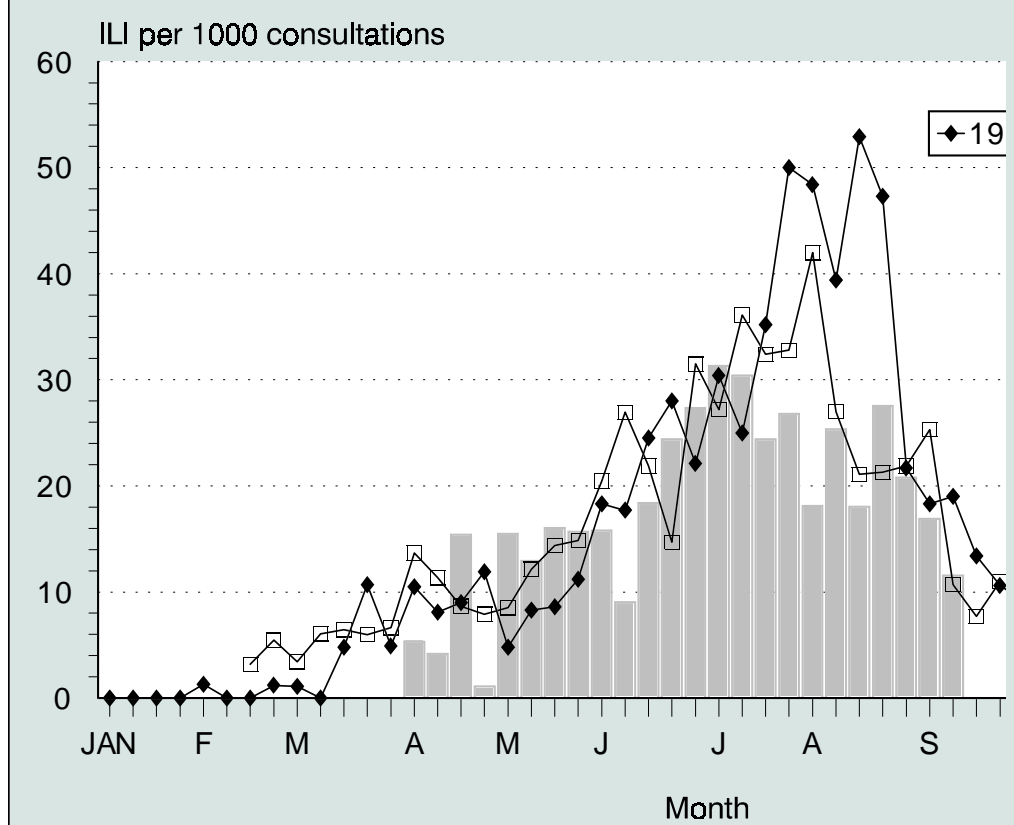

\section{FIGURE 4}

RESPIRATORY VIRUS ISOLATION RATES, NSW, 1990-1999

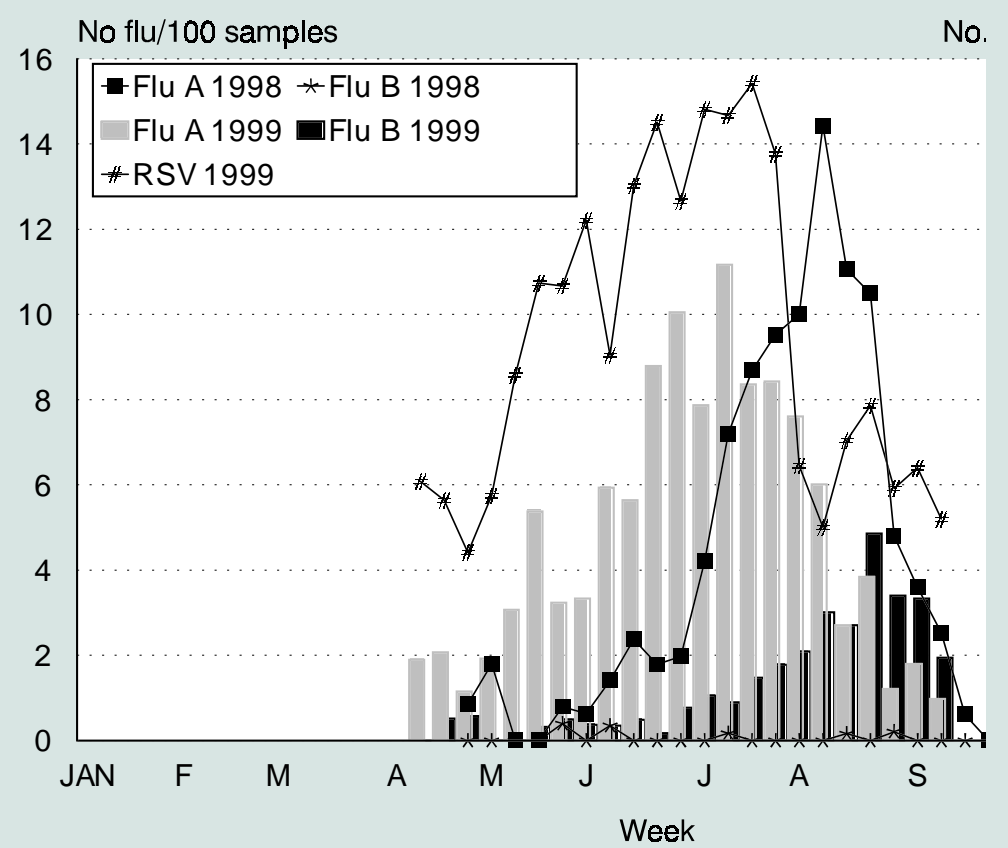




\section{continued from page 139}

To ensure that there is not an increase in the incidence of MDR TB and to promote best-practice management of MDR TB, an expert panel will be convened to review all cases identified as MDR TB in NSW. The panel will develop a case-management plan and will report to the Chief Health Officer.

\section{Referring MDR TB cases}

Cases can be directly referred to the panel via the State Tuberculosis Coordinator on receipt of bacteriological culture and sensitivity reports. The State Tuberculosis Coordinator can be contacted on (02) 93919277 at the NSW Department of Health.

In addition, clinicians can refer 'difficult to manage' cases of active tuberculosis to the panel for peer review and discussion. Once again, referral to the panel can be made via the State Tuberculosis Coordinator.

\section{The MDR TB panel}

The recommended composition of the panel includes:

- the attending physician and Area Tuberculosis Coordinator
- an infectious diseases physician

- a representative from the Institute of Clinical Pathology and Medical Research

- another physician expert in tuberculosis nominated by the Chief Health Officer

- a public health practitioner

- a NSW Health Department representative

- other relevant persons as defined by the panel chair.

To maintain Australia's excellent position in controlling tuberculosis, continuing improvements are needed in program management, disease surveillance and consistent control strategies, both within and between states.

\section{REFERENCES}

1. NH\&MRC Tuberculosis Working Party. Towards elimination of tuberculosis II (final draft). Canberra: National Health and Medical Research Council, May 1998.

2. Crofton J, Chaulet P, Maher D. Guidelines for the management of drug-resistant tuberculosis. Geneva: World Health Organization Global Tuberculosis Program, 1997. W

\section{NSW PUBLIC HEALTH BULLETIN}

The NSW Public Health Bulletin is a publication of the NSW Department of Health. The editor is Dr Lynne Madden, Manager, Public Health Training and Development Unit, NSW Department of Health. Dr Michael Giffin is production manager.

The Bulletin aims to provide its readers with population health data and information to motivate effective public health action.

\section{Submission of articles}

Articles, news and comments should be 1000 words or less in length and include a summary of the key points to be made in the first paragraph. References should be set out in the Vancouver style, described in the New England Journal of Medicine, 1997; 336: 309-315. Send submitted articles on paper and in electronic form, either on disc (Word for Windows is preferred), or by email. The article must be accompanied by a letter signed by all authors. Full instructions for authors are available on request from the editor.

\section{Editorial correspondence}

Please address all correspondence and potential contributions to The Editor, NSW Public Health Bulletin, Locked Mail Bag 961, North Sydney NSW 2059 or to Lmadd@doh.health.nsw.gov.au. Tel (02) 9391 9956, Fax (02) 93919232.

\section{Distribution}

Please contact your local Public Health Unit or telephone (02) 93919942 to obtain copies of the NSW Public Health Bulletin or to notify us of a change of address. The Bulletin can be accessed via the Internet from the Department's Web site: www.health.nsw.gov.au/public-health/phb/phb.html.

Back issues can be obtained from the Public Health Training and Development Unit, Locked Mail Bag 961, North Sydney NSW 2059. 